\title{
A VIDA BOA COM E PARA OUTREM: ÉTICA, ALTERIDADE E RECONHECIMENTO EM RICOEUR
}

\author{
Paulo Gilberto Gubert ${ }^{1}$
}

\begin{abstract}
Resumo: $\mathrm{O}$ artigo tem como objetivo principal investigar a inter-relação entre os conceitos éticos de alteridade e de reconhecimento em Ricœur. Primeiramente, demonstra-se o papel central da alteridade na ética ricœuriana. Em segundo lugar, com base na abordagem fenomenológica, evidencia-se que a polarização radicalizada nos termos ego e alter ego é inválida na medida em que não leva à valorização da singularidade do outro. Da relação entre a ética do respeito e a fenomenologia da simpatia, resulta que é preciso situar o caráter histórico e antropológico da alteridade, firmado mediante os conflitos inerentes à luta pelo reconhecimento. Todavia, a luta, a violência e o desprezo constituem formas de reconhecimento que negam a alteridade. Como alternativa ao reconhecimento pela luta, apresenta-se o modelo de reconhecimento pacífico que se estabelece por meio da generosidade e da gratidão, próprios da dinâmica da troca de dons.

Palavras-chave: ética - fenomenologia - alteridade - reconhecimento.
\end{abstract}

\section{Introdução}

No prefácio de $O$ si mesmo como um outro, Ricœur menciona três tipos de alteridade. O primeiro é a do corpo próprio ou da carne, na qual a carne é a mediadora entre o si e o mundo, este último tomado como estranho ao si; o segundo é a alteridade do outro, implicada na relação com o diverso de si; o terceiro é a alteridade da consciência moral, na qual se dá a relação do si com o si mesmo. De acordo com o propósito do artigo, será desenvolvida somente a alteridade do próximo, da relação curta² com o outro humano, pois é esta que parece estabelecer um vínculo direto com o reconhecimento mútuo. Neste sentido, apesar de ter manifestado decepção com a fenomenologia no que concerne ao problema do outro, Ricœur ${ }^{3}$ reconheceu que a quinta

\footnotetext{
${ }^{1}$ Professor de Filosofia na Universidade Católica de Pelotas (UCPel). E-mail: gilbertogubert@gmail.com

2 Segundo Ricœur (História e Verdade.), as relações curtas de amizade e de amor são relações raras, que surgem nas intermitências das relações longas, abstratas e anônimas.

${ }^{3}$ RICCEUR, Sympathie et respect: phénoménologie et éthique de la seconde personne.
} 
meditação cartesiana de Husserl $^{4}$ teve por mérito trazer à tona para o primeiro plano das discussões filosóficas a questão da alteridade.

O terceiro capítulo de $O$ percurso do reconbecimento demarca a elaboração do conceito de reconhecimento mútuo simbólico de Ricœur. Muito embora nosso autor procure desenvolver um conceito de reconhecimento pacífico, ele entende que é no medo da morte violenta infligida pelo outro, descrita por Hobbes 5 , e na luta por reconhecimento de Hegel 6 que se encontram os fundamentos para o desenvolvimento de um novo conceito de reconhecimento do outro.

Entendemos que no arcabouço do projeto ético ricœuriano ambos os conceitos alteridade e reconhecimento - são indissociáveis. Sendo assim, será necessário elucidar estes conceitos para que seja demonstrado por que esta relação de complementaridade é importante para a ética ricœuriana do bem viver com e para o outro.

Para tanto, o artigo apresenta-se subdividido em quatro partes. Primeiramente, será demonstrado como Ricœur entende a distinção entre si e eu, além da questão do si mesmo enquanto cogito partido (quebrado) pela alteridade do outro. Em segundo lugar, será apresentado de que forma a alteridade ocupa um espaço central na ética ricœuriana. $O$ terceiro ponto a ser discutido, será acerca da fenomenologia do alter ego e da complementaridade entre os conceitos de simpatia, respeito e luta. Por fim, será apresentado como Ricœur entende o conceito de reconhecimento mútuo e de que forma este conceito reforça a alteridade do outro sem invadir sua individualidade e, ainda, contribui para apaziguar os conflitos do cotidiano por meio da gratidão inerente ao dom.

\section{O cogito partido}

Em O si mesmo como um outro, Ricœur estabelece uma diferença fundamental entre si e eu. $\mathrm{O}$ eu é imediato e se exprime na primeira pessoa do singular: eu duvido, eu penso, eu sou. O si é reflexivo e é usado no modo infinitivo, ao ser aproximado do termo se; ambos se complementam na expressão lapidar do autor: "designar-se a si mesmo"7. Nesse caso, o termo mesmo é que permite distinguir entre dois modos de permanência no tempo de uma mesma identidade: a

\footnotetext{
4 Nesse sentido, não obstante tenha manifestado de antemão - no texto Na escola da fenomenologia - sua decepção com a fenomenologia no tocante ao problema do outro, Ricœur avalia que seu principal benefício foi trazer a questão da alteridade para o primeiro plano das discussões filosóficas. De acordo com o autor, a dialética entre o si e o diverso de si tomou corpo a partir da discussão que Husserl - fiel ao método fenomenológico - propôs, de que o alter deveria ser constituído na esfera de pertença do ego. Esquivou-se assim do solipsismo, mas permaneceu num egotismo.

${ }^{5}$ HOBBES, Leviatã ou matéria forma e poder de um estado eclesiástico e civil.

${ }^{6}$ HEGEL, Fenomenologia do Espirito.

7 "Se désigner soi-mème" (RICCEUR, Soi-même comme un autre, p. 12).
} 
mesmidade, marcada pelo caráter e a ipseidade que se apoia na promessa. ${ }^{8} \mathrm{O}$ caráter identifica o si consigo mesmo. A promessa possibilita uma abertura do si à alteridade do outro.

Por conseguinte, ressaltamos a relevância na filosofia ricœuriana do si no que concerne à questão fundamental do outro. $\mathrm{O}$ autor defende a necessidade de buscar uma reafirmação do si mesmo, de tal forma que não aconteça nem uma exaltação e nem uma humilhação do si, como se pode verificar nas filosofias do cogito e do anti cogito. As filosofias do cogito são as que tiveram início a partir do texto Meditações metafísicas de Descartes, formando a corrente do idealismo que perpassa por Kant, Fichte e culmina com o texto Meditações cartesianas de Husserl.

O cogito cartesiano é o princípio fundador das filosofias egológicas. Trata-se de um eu exaltado a ponto de perder a relação interlocutória com os outros, com sua própria historicidade e responsabilidade. Por outro lado, Ricœur afirma que a filosofia do anti cogito está desenvolvida de forma mais explícita e virulenta nos textos $O$ nascimento da tragédia e Fragmentos póstumos de Nietzsche. No segundo texto, Nietzsche afirma que a origem de todas as coisas é obra dos que pensam, imaginam, inventam. Sendo assim, até mesmo o sujeito é criado como todas as outras coisas. ${ }^{9}$ Nesse sentido, Ricœur assinala que Nietzsche, no exercício da dúvida hiperbólica, torna-se ele próprio o gênio maligno, denunciando a maior ilusão que ele percebe no cogito. Esta ilusão se caracteriza por uma inversão de causas e efeitos, uma vez que, no cogito, o eu é o efeito e não a causa do pensamento.

Ricœur, por sua vez, não pretende estabelecer uma nova forma de exaltação, nem de destituição do si. Ele defende a tese de um si que é um cogito partido; ou seja, um cogito que é constituído, atravessado pela alteridade, tornando-se assim, um sujeito entre outros sujeitos. É nesse sentido que ele reafirma a existência de um sujeito, pois só poderemos "compreender o que é o sujeito humano se compreendermos de que maneira esse outro está presente nele de forma assim tão íntima". ${ }^{10}$ Portanto, não se trata mais de um cogito que busca em si os fundamentos do

\footnotetext{
8 É justamente por meio da distinção entre caráter e promessa que Ricœur desenvolve um conceito de identidade pessoal que se constitui na dimensão temporal da existência humana e se fundamenta nos princípios da mesmidade (idem) e da ipseidade (ipse). Nesse sentido, quando falamos de nós mesmos, usamos dois modelos de permanência no tempo: "o caráter e a palavra considerada [promessa]. Num e noutro, reconhecemos de bom grado uma permanência que dissemos ser de nós mesmos" (RICCEUR, O si-mesmo como um outro, p. 143). A mesmidade constitui-se de um princípio de permanência invariável no tempo, mesmo quando pareça ter sido tudo mudado. Sendo assim, o caráter é o conjunto total das marcas distintivas que permitem reidentificar um sujeito como o mesmo. Trata-se de uma continuidade ininterrupta, aquilo que permanece no tempo. Por outro lado, o modo de proceder que caracteriza a promessa é a constância a si, ou ipseidade. Para Ricœur, "uma coisa é a perseveração do caráter; uma outra, a perseveração da fidelidade à palavra dada. Uma coisa é a continuação do caráter; uma outra a constância na amizade" (O si-mesmo como um outro, p. 149). Além disso, "a ipseidade é a maneira de [uma pessoa] se comportar tal que o outro possa contar com ela. Porque alguém conta comigo, eu sou responsável por minhas ações diante de um outro" (RICCEUR, O si-mesmo como um outro, p. 195, grifo do autor). Neste ponto, percebe-se que a ipseidade estabelece uma dialética que vai para além do si. Na mesmidade, o outro é apenas oposto ou distinto de mesmo. A ipseidade, por sua vez, representa uma abertura à alteridade, por meio da promessa (RICCEUR, O si-mesmo como um outro, p. 195).

${ }^{9}$ NIETZSCHE, Fragmentos póstumos.

10 GENTIL, "Paul Ricœur: A presença do outro", p. 09.
} 
conhecimento, do mundo, de Deus, de si mesmo e até do outro. Trata-se de um sujeito que pede para ser reconhecido com e para o outro.

De acordo com esta perspectiva, fica evidente que o sujeito não vive sozinho no mundo. Ao contrário, o sujeito ricœuriano vive e convive com outros que podem estar próximos ou distantes, em uma relação que envolve tempo e espaço. No tempo são os antecessores, para com os quais o sujeito tem uma dívida que deve reconhecer; e também os sucessores, que devem ser levados em consideração nas consequências das ações e, portanto, nas deliberações e decisões deste sujeito. No espaço "são os contemporâneos, próximos e distantes, da intimidade do amor à impessoalidade do anonimato, passando pela pessoalidade da amizade". ${ }^{11}$

Nesse sentido, é preciso salientar que o projeto personalista de E. Mounier também exerce influência sobre o pensamento de Ricœur. Mounier afirma, em seu texto $O$ personalismo, que "pessoa não é uma coisa que se pode encontrar no fundo das análises, ou uma combinação definível de aspectos. Se fosse uma súmula, poderia ser inventariada, mas é, exatamente, o não inventariável". ${ }^{12}$ Ricœur, em seu texto História e Verdade, ${ }^{13}$ preserva o conceito mounieriano de pessoa, acrescentando o dado fundamental de que cada pessoa está em uma constante abertura ao diálogo com o outro.

É em virtude dessa relação originária com o outro, que não apenas coexiste, mas também constitui e é constituído pelo sujeito, que a questão do outro é fundamental para a ética de Ricœur.

\section{Viver bem com e para o outro: a ética, a moral e a sabedoria prática}

O ponto de partida da ética ricœuriana é a perspectiva aristotélica da "vida boa com e para os outros nas instituições justas". ${ }^{14}$ Para Aristóteles, ${ }^{15}$ a primeira garantia da vida boa está na segurança de que o homem pode ser autor de seus próprios atos, julgando-os racionalmente.

Neste contexto, a ética se caracteriza pela finalidade e pelo objetivo a ser atingido, isto é, que se possa viver bem. Alcançar a realização pessoal significará o coroamento e o fim último das ações. A vida boa representa a possibilidade que cada pessoa tem de ser tanto autora quanto capaz de julgar seus próprios atos racionalmente, ou seja, capaz de estimar a si mesma. No entanto, a vida boa não é feita de um homem só. Aristóteles afirma ainda que o homem necessita de amigos, que estabeleçam relações mútuas, em que cada um deseja o bem para o outro. Neste sentido, verifica-se

11 GENTIL, "Paul Ricœur: A presença do outro", p. 07.

12 MOUNIER, O Personalismo, p. 84.

${ }^{13}$ RICCEUR, História e verdade, p. 135.

${ }^{14}$ RICCEUR, O si-mesmo como um outro, p. 202. Em virtude dos propósitos deste artigo, não serão apresentadas as questões referentes às instituições e à justiça. Contudo, vale mencionar que, para Ricœur, "entre todas as virtudes, a da justiça é a que, por excelência e por constituição, é voltada para outrem. Pode-se até dizer que a justiça constitui o componente de alteridade de todas as virtudes que ela arranca do curto-circuito entre si mesmo e si mesmo." (A memória, a história, o esquecimento., p. 101).

15 ARISTÓTELES. Ética a Nicômaco. 
em Aristóteles que "a amizade perfeita é a dos homens que são bons e afins na virtude, pois esses desejam igualmente bem um ao outro enquanto bons, e são bons em si mesmos". ${ }^{16}$

Todavia, Ricœur considera não ser possível visualizar em Aristóteles um conceito franco de alteridade. Segundo Rossatto, "a amizade aristotélica denota uma relação insuficiente entre dar e receber, posto que se sustenta unicamente na suposição de que há uma distribuição simétrica de bens entre iguais". ${ }^{17}$ Por isso, Ricœur recorre ao conceito de solicitude ${ }^{18}$ enquanto possibilidade de abertura e de acolhida do outro. A solicitude não advém da potência de agir de um sujeito, mas surge justamente da identificação com o outro sofredor no momento de sua fraqueza, em que o si se permite afetar com o sofrimento do outro, garantindo uma autêntica reciprocidade entre ambos.

Num segundo momento de desenvolvimento de sua ética, o autor trata da norma moral kantiana. Com relação à perspectiva ética aristotélica, a norma moral terá a função de testá-la e, respectivamente, legitimá-la, reconhecendo-a, inclusive, como seu próprio fundamento. O imperativo categórico, ${ }^{19}$ ao ser confrontado com a estima de si, encontra semelhanças, especialmente no que diz respeito à capacidade de autodeterminação racional.

Para Ricœur, o imperativo categórico não pode ser entendido como uma forma de solipsismo moral, muito embora o conceito de autonomia ${ }^{20}$ kantiano pareça conduzir a uma egologia já que, inicialmente, o sujeito parece não depender do outro em nenhum momento. Tudo parece se resolver na autonomia do si que se autolegisla. Contudo, o autor alerta que não se trata de uma teoria baseada apenas no si, mas de uma busca pela "universalidade de querer, apanhada nesse momento abstrato onde ela não é ainda distribuída entre a pluralidade das pessoas". ${ }^{21}$

A questão fundamental, que nutre esta interpretação ricœuriana, reside na segunda formulação do imperativo categórico: "age de modo que trates a humanidade, tanto na tua pessoa, quanto na pessoa de qualquer outro, sempre e simultaneamente como fim e nunca simplesmente como meio". 22

\footnotetext{
${ }^{16}$ ARISTÓTELES. Ética a Nicômaco, p. 181.

${ }^{17}$ ROSSATTO, Viver bem, p. 30.

18 "A solicitude [...] introduz um novo tipo de relação que torna possível restituir o equilíbrio entre partes inicialmente desiguais" (ROSSATTO, "Viver bem", p. 30).

${ }^{19}$ A primeira formulação do imperativo categórico "Age apenas segundo uma máxima tal que possas ao mesmo tempo querer que ela se torne lei universal" (KANT, Fundamentação da metafísica dos costumes., p. 59), representa um dos pressupostos básicos da filosofia moral kantiana.

${ }^{20}$ Sobre o princípio de autonomia da vontade, Kant afirma tratar-se de um "conceito segundo o qual todo o ser racional deve considerar-se como legislador universal por todas as máximas da sua vontade para, deste ponto de vista, se julgar a si mesmo e às suas ações" (Fundamentação da metafísica dos costumes., p. 75). Sendo assim, a "autonomia é pois o fundamento da dignidade da natureza humana e de toda a natureza racional" (Fundamentação da metafísica dos costumes., p.79, grifo do autor).

${ }^{21}$ RICCEUR, O si-mesmo como um outro, p. 247.

${ }^{22}$ KANT, Fundamentação da metafísica dos costumes, p. 69.
} 
Por meio da segunda formulação do imperativo categórico, considera-se a humanidade não enquanto soma matemática de indivíduos, mas a partir do ponto de vista do respeito ${ }^{23}$ que se deve a cada pessoa em particular. Como avalia Ricœur, não é possível estabelecer vínculos entre o si e o outro, se não for "determinado o que, na minha pessoa e naquela do outro, é digno de respeito". ${ }^{24}$

Neste ponto é que a solicitude, somada ao respeito, estabelece uma relação de complementaridade, por meio da Regra de Ouro. ${ }^{25}$ A solicitude permite ir além do respeito ao outro oriundo da interdição da lei do imperativo; por meio de sua espontaneidade benevolente sua principal característica - ela possibilita a acolhida do outro. Segundo Rossatto, abre-se "assim o caminho para a compensação da desigualdade decorrente do sofrimento em que 'o outro parece reduzido à condição de apenas receber". ${ }^{26}$

A sabedoria prática ${ }^{27}$ representa, neste contexto, uma tentativa de equilíbrio que busca salvaguardar ambas as propostas - a teleológica e a deontológica. Para tanto, Ricœur salienta que os

${ }^{23}$ De acordo com Kant, "aquilo que eu reconheço imediatamente como lei para mim, reconheço-o com um sentimento de respeito que não significa senão a consciência da subordinação da minha vontade a uma lei, sem intervenção de outras influências sobre a minha sensibilidade. [...] $\mathrm{O}$ objeto do respeito é portanto simplesmente a lei, quero dizer aquela lei que nos impomos a nós mesmos, e no entanto como necessária em si. Como lei que é, estamos-lhe subordinados" (Fundamentação da metafísica dos costumes., p. 32, grifos do autor). Na esteira de Ricœur, Rossatto entende que "a introdução da noção de respeito traz consigo a distinção kantiana entre pessoa e coisa, assinalada na segunda formulação do imperativo categórico. Passa-se, então, a entender que o reconhecimento do outro não se deve dar com base nos moldes da relação pessoa-coisa, mas segundo a relação entre pessoas. Em consequência disso, o outro terá de ser tomado como fim em si mesmo, e nunca como meio utilizado em próprio benefício para atingir um fim" "Viver bem", p. 32).

${ }^{24}$ RICCEUR, O si-mesmo como um outro, p. 261.

${ }^{25}$ A Regra de Ouro pode ser compreendida sob dois enfoques. O primeiro vem do Talmud: "Não fazes a teu próximo o que tu detestarias que te fosse feito. Está aí a lei completa; o resto é comentário" (Talmud de Babilônia apud RICCEUR, O si-mesmo como um outro, p. 256). O segundo enfoque, de fórmula positiva, encontra-se no Evangelho de Mateus (Mt 22,39): “Amarás o teu próximo como a ti mesmo". Segundo Ricœur, Kant quase não cita a Regra de Ouro, por considerá-la imperfeitamente formal. Primeiro, ela é parcialmente formal porque não diz sobre o que o outro gostaria ou não que lhe fosse feito. Em segundo lugar, é imperfeitamente formal, porque se refere a amar e detestar, entrando, portanto, no campo das inclinações. É pela prova de universalização da segunda formulação do imperativo que se poderá purificar as máximas do amor e do ódio em favor do princípio de autonomia. Portanto, como avalia Ricour, "amor e ódio são os princípios subjetivos de máximas que, como empíricas, são inadequadas à exigência de universalidade" (O si-mesmo como um outro, p. 261). Por outro lado, Ricœur afirma que a Regra de Ouro "es el punto de partida en la reflexión moral. Es un punto de partida en la medida en que la idea del otro debe ser formada con toda la fuerza de una alteridad que me ordena ser responsable, como lo proclama Levinas" (La naturaleza y la norma: lo que nos hace pensar, p. 235, grifo nosso).

${ }^{26}$ ROSSATTO, Viver bem, p. 30.

${ }^{27}$ A sabedoria prática não representa uma terceira instância, para além da ética e da moral. Sua função consiste em demonstrar que existem situações nas quais a moral da obrigação entra em aporias que somente poderão ser resolvidas a partir do retorno à intuição primeira da ética (RICCEUR, O si-mesmo como um outro, p. 281). Ricœur elenca os três traços constituintes da sabedoria prática: o princípio do respeito kantiano, a justa medida aristotélica e a convicção "que sela a decisão [e que] beneficia-se então do caráter plural do debate" $(O$ si-mesmo como um outro, p. 319). A convicção é oriunda do aconselhamento e do diálogo com os mais sábios e esclarecidos dentre os homens e as mulheres. Conforme avalia Ricœur, "o phronimos não é forçosamente um homem só" (O si-mesmo como um outro, p. 319, grifo do autor). 
conflitos gerados pela universalidade da norma moral deverão ser prudentemente analisados a partir da singularidade de cada caso e de cada sujeito envolvido. Isto significa que a conviç̧ão oriunda da sabedoria prática e aplicada aos conflitos do cotidiano denota uma tentativa de salvaguardar a singularidade do outro ante a universalidade da norma. Nesse sentido, é imprescindível que o sofrimento do outro não seja obliterado pela indistinção da lei. O respeito ao outro deve ser anterior ao respeito pela lei e não o contrário.

A ética kantiana do respeito, por sua vez, precisará assumir uma posição fundamental em relação à fenomenologia da simpatia husserliana, na medida em que preserva a relação pessoapessoa ante a relação pessoa-coisa.

\section{A alteridade do outro: implicações ético-fenomenológicas}

A dialética do si com o diverso de si possui um caráter ético-fenomenológico. ${ }^{28}$ Para Ricœur, a dialética entre o si e o diverso de si tomou corpo a partir da discussão que Husserl - fiel ao método fenomenológico - propôs, de que o alter deveria ser constituído na esfera de pertença do ego. Nesse sentido, Husserl afirma que "é necessário dar-se conta do sentido de intencionalidade explícito e implícito, no qual, sobre o fundo do nosso ego transcendental, se afirma e se manifesta o alter ego". ${ }^{29}$ No entanto, o próprio Husserl percebe o quanto esta afirmação pode ser problemática: "como é que o meu ego, no interior do seu ser próprio, pode, de alguma maneira, constituir 'o outro' 'justamente como the sendo estranho', quer dizer, conferir-lhe um sentido existencial que o coloca fora do conteúdo concreto do 'eu próprio' concreto que o constitui [?]”. 30

\footnotetext{
28 Neste ponto, especialmente no que concerne à questão da alteridade, Lévinas é um filósofo digno de menção, por sua relevante contribuição acerca desta temática. Contudo, como ambas as críticas - tanto de Ricœur, quanto de Lévinas - se dirigem, em primeiro lugar, a Husserl e também para não nos estendermos muito, optamos por utilizar esta breve nota explicativa. De acordo com Ricœur (Soi-même comme un autre), Lévinas (Totalidade e infinito) utiliza a fenomenologia como método, mas pensa uma filosofia da subjetividade polarmente oposta à de Husserl (Meditações cartesianas: introdução à fenomenologia). Isto significa que, enquanto Husserl mantém o ego na subjetividade transcendental, da qual deriva o alter ego, Lévinas aposta na radicalidade do totalmente outro, definido pela exterioridade de um eu separado do outro. Para Lévinas, "o eu que pensa dá por si a pensar ou espanta-se com as suas profundidades e, em si, é um outro [...]. Dá por si a pensar e surpreende-se como dogmático, estranho a si próprio. Mas o Eu é o Mesmo perante a alteridade, confunde-se consigo, incapaz de apostasia em relação a esse 'si' surpreendente" (Totalidade e infinito, p. 24). Por conseguinte, o outro é absolutamente outro, não depende e não se limita ao mesmo. É metafísico. "O Outro metafísico é outro de uma alteridade que não é formal, de uma alteridade que não é um simples inverso da identidade, nem de uma alteridade feita de resistência ao Mesmo, mas de uma alteridade anterior a toda a iniciativa, a todo o imperialismo do Mesmo [...]. O absolutamente Outro é Outrem; não faz número comigo. A coletividade em que eu digo 'tu' ou 'nós' não é um plural de 'eu'. Eu, tu, não são indivíduos de um conceito comum" (LÉVINAS, Totalidade e infinito, p. 26, grifo do autor).

${ }^{29}$ HUSSERL. Meditações cartesianas: introdução à fenomenologia , p. 116.

${ }^{30}$ HUSSERL. Meditações cartesianas: introdução à fenomenologia , p. 121.
} 
Ricœur entende que, se por um lado, o idealismo husserliano exige que "o outro, como a coisa, seja uma unidade de modos de aparição, um sentido ideal pressuposto"; 31 por outro lado, conferir presença ao outro significa “'transgredir' a minha esfera própria de experiência, para fazer surgir, nos limites do meu vivido, um acréscimo de presença, incompatível com a inclusão de todo sentido em meu vivido". ${ }^{32}$ Sendo assim, o idealismo esquivou-se do solipsismo, mas permaneceu num egotismo. ${ }^{33}$

Nosso autor entende que a fenomenologia não ofereceu uma resposta satisfatória, pois manteve o ego na subjetividade transcendental, da qual deriva o alter ego. Como uma tentativa de resposta à fenomenologia, Ricœur publicou o artigo "Simpatia e respeito: fenomenologia e ética da segunda pessoa", no qual a discussão se estabelece entre Husserl e Kant.

Ricœur introduz o texto com uma crítica à fenomenologia ao afirmar que não se dá fenômeno sem alguma coisa que aparece; e que, neste caso, não se trata de uma coisa, mas de alguém. Isso significa que é preciso que haja "um reconhecimento do outro, ligado ao momento formal da ética. Mediante este ato de reconhecimento, a pretensão do eu a se posicionar por si e para si encontra seu limite". 34

$O$ autor entende que o ato de reconhecimento envolve um entrecruzamento da fenomenologia da simpatia com a ética do respeito. Mas o que o autor entende por simpatia e qual a relação desta com o respeito?

Simpatia é compartilhar um sentimento com outra pessoa sem repeti-lo nem experimentálo por duplicação como um vivido semelhante. Trata-se de um sentir com, que não pode tornar-se um sentir como, pois isto seria contágio afetivo, que é patológico porque representa uma fusão com o outro. O contágio afetivo é o perigo constante que paira sobre a simpatia.

Portanto, a simpatia possui uma tendência romântica de se perder no outro ou de absorvêlo, ou seja, ela pode se tornar uma fusão afetiva. O papel do respeito, neste contexto, é o de proteger a simpatia dessa tendência, buscando dar-lhe uma justificação crítica. Ricœur afirma que "o respeito aprofunda a 'distância fenomenológica' entre os seres, pondo o outro ao abrigo das invasões da minha sensibilidade indiscreta: a simpatia toca e devora o coração, o respeito observa

\footnotetext{
${ }^{31}$ RICCEUR, Na escola da fenomenologia, p. 311.

32 RICCEUR, Na escola da fenomenologia, p. 311.

${ }^{33}$ Nesse sentido, é a tese husserliana da apreensão analogizante do outro que representa, segundo Ricœur, o ponto de equilíbrio entre "a preocupação descritiva de respeitar a alteridade do outro e a preocupação dogmática de fundar o outro na esfera primordial de pertença" ( $N a$ escola da fenomenologia, p. 313). Para Husserl, a analogia é o ato que permite ao ego perceber o outro como algo mais do que um simples organismo (corpo físico). Por meio da analogia se admite a intencionalidade do outro enquanto co-existente. No entanto, ele salienta que a co-existência "não é nem nunca poderá estar aí 'em pessoa" (Meditaçoes cartesianas: introdução à fenomenologia, p. 139). Por conseguinte, Ricœur esclarece que, graças à teoria da apreensão analogizante, "pode-se vencer o solipsismo sem o sacrifício da egologia. Noutros termos, pode-se explicar a transgressão da esfera do próprio, confirmando ao mesmo tempo o primado da experiência originária do eu" ( $\mathrm{Na}$ escola da fenomenologia, p. 227).

${ }^{34}$ RICCEUR, Na escola da fenomenologia, p. 331.
} 
de longe". 35 Além disso, é através do respeito que "eu me compadeço ao mesmo tempo com a dor ou com a alegria do outro como sua e não como minha". ${ }^{36}$ Sendo assim, o respeito justifica criticamente a simpatia, pois elimina seu equívoco, mantendo a alteridade dos seres que a fusão afetiva tende a anular.

O respeito reordena interiormente os afetos e, por isso, pode ser chamado de momento transafetivo ${ }^{37}$, segundo Ricœur. O autor salienta ainda que o respeito, na filosofia kantiana, é designado como único sentimento "espontaneamente produzido, em oposição aos outros afetos que são sofridos ou recebidos por influência". ${ }^{38}$ Dessa forma, chega-se ao momento do respeito prático puro, que revela, por sua vez, o sentido da simpatia.

Simpatia e respeito significam, para Ricœur, um só e mesmo vivido, de tal forma que "a simpatia é o respeito considerado na sua matéria afetiva, a saber, em sua raiz de vitalidade, em seu impulso e sua confusão; já o respeito vem a ser a simpatia considerada em sua forma prática e ética, isto é, como posição ativa de um outro eu mesmo, de um alter ego". ${ }^{39}$

Ricœur entende, portanto, que há uma afinidade da fenomenologia da simpatia com a ética do respeito. Contudo, o respeito significa aqui apenas uma tomada de posição diante do outro, ou seja, uma atestação de sua existência-valor, que necessariamente deve buscar o complemento da fenomenologia da simpatia no sentimento e na ação.

\footnotetext{
35 RICCEUR, Na escola da fenomenologia, p. 323.

${ }^{36}$ RICCEU, Na escola da fenomenologia, p. 323.

${ }_{7}$ Sobre o sentimento de respeito, Kant assevera que "não é um sentimento recebido por influência; é, pelo contrário, um sentimento que se produzpor si mesmo através dum conceito da razão, e assim é especificamente distinto de todos os sentimentos do primeiro gênero que se podem reportar à inclinação ou ao medo" (Fundamentação da metafísica dos costumes, p.32, grifos do autor).

38 RICCEUR, Na escola da fenomenologia, p. 325

${ }^{39}$ RICCEUR, Na escola da fenomenologia, p. 324.
} 
A ação, por sua vez, situa os sujeitos na história por meio dos conflitos inerentes à luta pelo reconhecimento, conforme descrito na dialética do senhor e do escravo, de Hegel ${ }^{40}$. Para Ricœur, a luta assegura simultaneamente "o momento dialético e o momento histórico que faltam tanto à ética do respeito quanto à fenomenologia da simpatia". ${ }^{41}$

Todavia, a luta não é o ponto final no que concerne ao reconhecimento. Ricœur considera que existem formas positivas de reconhecimento do outro que podem substituir a luta pelo reconhecimento por uma alternativa não violenta para a solução dos conflitos.

\section{O reconhecimento mútuo}

A temática do reconhecimento mútuo envolve uma dialética entre reflexividade e alteridade, desenvolvida por Ricœur no Percurso do reconbecimento, que visa assegurar que tanto o si quanto o outro sejam reconhecidos mutuamente, não obstante a realidade cotidiana de conflitos em que ambos se situam.

Nesse sentido, o autor avalia que a luta por reconhecimento hegeliana ${ }^{42}$ ambiciona oferecer um fundamento moral capaz de refutar a negação do reconhecimento por meio da violência e do

\footnotetext{
${ }^{40}$ Hegel, na Fenomenologia do Espírito, desenvolve a dialética do senhor e do escravo para demonstrar como se dá o reconhecimento entre duas consciências que desejam ser reconhecidas. Para tanto, a consciência-de-si sai da condição de si mesma, - portanto, nega sua própria condição - e, durante a operação de reconhecimento, suprassume o outro, "pois não vê o Outro como essência, mas é a si mesma que vê no Outro" (HEGEL, Fenomenologia do espirito, p. 143, grifo do autor), para depois retornar a si mesma. No entanto, o mesmo movimento é simultaneamente praticado pela outra consciência-de-si. Dessa forma, afirma Hegel, "eles se reconbecem como reconhecendo-se reciprocamente" (Fenomenologia do espirito, p. 144, grifos do autor). "Esse reconhecimento é [num primeiro momento] um enfrentamento, uma busca a morte da outra para que seu desejo seja satisfeito" (SOARES, Consciência-de-si e reconbecimento na Fenomenologia do espirito e suas implicações na filosofia do direito, p. 60). Entretanto, o reconhecimento tem por função conservar o outro, evitando sua anulação através da morte (SOARES, Consciência-de-si e reconhecimento na Fenomenologia do espirito e suas implicações na filosofia do direito, p. 60). "O reconhecimento suprassume a luta de vida e morte e define os papéis das consciências-de-si, a saber, do senhor e do escravo no mundo, o senhor em busca do gozo e o escravo como mediador da relação do senhor e o objeto desejado" (SOARES, Consciência-de-si e reconbecimento na Fenomenologia do espirito e suas implicasóes na filosofia do direito, p. 61). Ricœur assinala que a dialética culmina em um distanciamento, "numa espécie de dar as costas do senhor e do escravo, os quais se reconhecem um ao outro como compartilhando o pensamento [...]. O senhor e o escravo, um imperador e um escravo, dizem ambos 'nós pensamos'. E como os dois pensam, senhor ou escravo são indiferentes [cada um em relação ao outro]" ("A luta por reconhecimento e a economia do dom", p. 357).

${ }^{41}$ RICCEUR, Na escola da fenomenologia, p. 328.

42 Ricœur destaca esta dialética como um modelo de revelação da existência do outro que se dá pela negatividade. "A luta que dramatiza o problema do outro não estará mais em concordância com a realidade cotidiana do que a compaixão? Em suma, é-se tentando a pensar que a oposição das consciências é a chave de sua alteridade; outras porque cada uma busca a morte da outra" (Na escola da fenomenologia, p. 319).
} 
medo que caracterizam o estado de natureza hobbesiano. ${ }^{43}$ Contudo, até mesmo a reconstrução e atualização apresentada por Axel Honneth ${ }^{44}$ - do problema hegeliano do reconhecimento - recai em uma fenomenologia do desprezo que não é capaz de solucionar o problema da luta infindável. 45

A questão nodal acerca do reconhecimento em Hegel é a da oposição de consciências, que se reconhecem somente ao negarem umas às outras. Neste contexto, portanto, a oposição é a característica principal da alteridade. Por conta disso, Ricœur apresenta sua tese de que "a luta pelo reconhecimento se perderia na consciência infeliz ${ }^{46}$ se não fosse dada aos humanos a possibilidade de ter acesso a uma experiência efetiva, embora simbólica, de reconhecimento mútuo, com base no modelo do dom cerimonial recíproco". 47

Por meio da tese do reconhecimento mútuo simbólico é que o autor vislumbra uma possibilidade de alteridade positiva, uma vez que, na dinâmica das trocas de dons, ambos os protagonistas são reconhecidos na troca. É justamente essa relação entre protagonistas que o autor procura salvaguardar, por meio de experiências de reconhecimento pacificado, delineadas, em primeiro lugar, pela desmesura do ágape que, por sua vez,

não comporta senão um desejo, o de dar; é a expressão de sua generosidade. Ele surge então no meio de um mundo costumeiro em que o dom assume a forma social de uma troca na qual o espírito de justiça se expressa, como no resto de seu reino, pela regra de equivalência. Quaisquer que sejam as origens arcaicas da economia do dom [...], o dom ainda está presente em nossas sociedades, aliás dominadas pela economia mercantil onde tudo tem preço. 48

\footnotetext{
$43 \mathrm{O}$ estado de natureza se caracteriza pela guerra de todos os homens contra todos os homens e se funda em três paixões primitivas: a competição, a desconfiança e a glória. "A primeira leva os homens a atacar os outros tendo em vista o lucro; a segunda, a segurança; e a terceira, a reputação" (HOBBES, Leviatã ou matéria forma e poder de um estado eclesiástico e civil., p. 75).

${ }^{44}$ HONNETH, Luta por reconhecimento: a gramática moral dos conflitos sociais.

45 Segundo Ricœur, "pode-se dizer que todo o empreendimento de Honneth subsequente a Hegel é justamente a noção de conflito destruidor do reconhecimento, porque é onde essa fenomenologia encontra talvez o seu limite e pede uma retomada da questão acerca do papel quase fundador atribuído à noção de conflito e de luta" (“A luta por reconhecimento e a economia do dom”, p. 361).

46 Para Hegel, "a consciência infeliz é a consciência-de-si como essência duplicada e somente contraditória. Essa consciência infeliz [é] cindida dentro de si, já que essa contradição de sua essência é, para ela, uma consciência" (HEGEL, Fenomenologia do espirito, p. 159, grifos do autor). Portanto, a contradição está no fato de que a consciência de si tenta - sem sucesso - incorporar a consciência do outro em sua essência. Ricœur salienta que essa contradição gera uma insatisfação infinita, que resulta em uma interminável luta por reconhecimento. Por conseguinte, ele afirma que infelicidade da consciência é um "produto da civilização" (RICEER, "A luta por reconhecimento e a economia do dom", p. 363).

47 RICCEUR, Percurso do reconhecimento, p. 165. Ademais, de acordo com Ricœur, "na relação de presentear, de troca, de benefício, temos uma experiência viva de reconhecimento. Não estamos mais em busca do insaciável, mas temos algum tipo de pequena felicidade em reconhecer e em ser reconhecido" ("A luta por reconhecimento e a economia do dom", p. 366).

48 RICCEUR, Percurso do reconhecimento, p. 238.
} 
Nesse sentido, o autor salienta que o ágape, por não se utilizar de comparações ou de cálculos, constituirá o elemento que faltava ao problema da economia do dom ${ }^{49}$ de Marcel Mauss, ${ }^{50}$ a saber, como resolver o enigma da obrigação da retribuição inerente ao dom. De acordo com Ricœur, Mauss simplesmente adotou a explicação dada pelos indígenas maoris da Nova Zelândia. Para estes, existe uma força mágica, denominada hau, que faz com que o dom retorne ao seu doador. ${ }^{51}$

Ricœur, por sua vez, entende que o dom pode ser mais bem compreendido quando é comparado ao mercado, pois o mercado moderno representa a ausência de dom nas transações entre indivíduos. ${ }^{52} \mathrm{E}$ justamente a ideia de que ainda existem bens não comercializáveis que possibilita ao autor desenvolver a temática do dom cerimonial recíproco como modelo de reconhecimento, na esteira da noção de sem preço, tomada do texto "O preço da verdade" de Marcel Hénaff. A estratégia proporcionada pela categoria do sem preço é garantir a diferenciação entre dom e mercado. ${ }^{53}$

Isto significa que quando se trata da troca de dons, a lógica de mercado deve ceder espaço à gratidão. A relação que se estabelece entre os protagonistas da troca de dons somente fica preservada à medida que a dinâmica entre a generosidade do dom e a gratidão do contradom se desvencilha do enigma da retribuição polarizado entre o dar e o retribuir - e centra-se no receber. A gratidão daquele que recebe leva-o a retribuir. Este gesto, por sua vez, implica em uma nova gratidão, desta vez, daquele que ofereceu um dom e que agora se torna o donatário. Por conseguinte, é a gratidão inerente ao gesto de receber que demarca o pináculo central tanto do caráter cerimonial da troca de dons, quanto do reconhecimento da alteridade do outro. Desta relação mútua, brota uma alteridade que assegura o respeito à intimidade do outro, salvaguardando seu caráter insubstituível e sancionando que o reconhecimento mútuo simbólico - a cada vez representa uma confirmação positiva da alteridade do outro.

\footnotetext{
49 Ricœur afirma, por um lado, que Mauss procura não opor "o dom à troca, mas à forma comercial da troca, ao cálculo, ao interesse" (A memória, a história, o esquecimento., p. 486); por outro lado, sua interpretação demonstra que, se Mauss trata de uma economia, "que dizer que o dom se encontra na mesma direção que a economia comercial" (2010, p. 363).

50 MAUSS, Sociologie et anthopologie.

51 RICCEUR, Percurso do reconbecimento, p. 240.

52 Ricœur esclarece que, "no mercado não há obrigação de retribuir porque não há exigência; o pagamento coloca um fim às obrigações mútuas dos atores da troca" (Percurso do reconhecimento, p. 245).

${ }^{53}$ Neste sentido, Ricœur salienta que foi Sócrates quem inaugurou a discussão que se situa na interseção entre verdade e dinheiro (Percurso do reconhecimento, p. 247). Ao contrário dos sofistas, Sócrates ensinava a verdade sem cobrar nada. Dessa forma, surge a relação de inimizade entre a verdade e o dinheiro, que perpassa a história até a contemporaneidade.
} 


\section{Considerações finais}

$\mathrm{O}$ ato de reconhecer pacificamente a alteridade do outro - por meio da dinâmica do dom e do contradom - é uma aposta de Ricœur que não é meramente utópica, pois é impossível cessar em definitivo com os conflitos do cotidiano. Isto significa que, o reconhecimento mútuo simbólico, a cada vez que é vivenciado, representa apenas uma suspensão temporária da luta por reconhecimento. As raras experiências do dom não estão desvinculadas dos conflitos que as sucedem e as precedem.

Nesse sentido, Ricœur propõe uma reinterpretação do problema do reconhecimento a partir de uma tomada de posição do outro que não seja motivada apenas pela luta ou pela violência. A palavra final não pode ser dada a nenhuma destas alternativas, pois elas representariam duas únicas possibilidades de relação com o outro: ignorá-lo ou eliminá-lo.

Enfim, a discussão sobre a complementaridade dos conceitos de alteridade e de reconhecimento só faz sentido na medida em que a singularidade insubstituível de cada pessoa for tomada em consideração. Existe aí uma intimidade que não deve ser violada, apenas reconhecida. Somente neste estágio será possível pensar uma ética da alteridade.

\section{THE GOOD LIFE WITH AND FOR OTHERS: ETHICS, OTHERNESS AND RECOGNITION IN RICEUR}

Abstract: The main goal of this paper is to investigate the interrelationship between ethical concepts of otherness and recognition in Ricœur. First, it is demonstrated the central role of the otherness in the Ricœurian ethics. Secondly, based on the phenomenological approach, it is evident that the radical polarization in the terms 'ego' and 'alter ego' is invalid insofar it does not lead the valorization of other's uniqueness. The relationship between the ethic of respect and phenomenology of the sympathy results in necessity to situate the historical and anthropological character of the otherness, consolidated by the inherent conflicts of the struggle for recognition. However, the struggle, the violence and the disregard are forms of recognition wich deny the othemess. As an alternative to the struggle for recognition, it is presented a model of peaceful recognition that is established through generosity and gratitude, inherents to the dynamics of exchange of gifts.

Keywords: ethics - phenomenology - otherness - recognition.

\section{Referências bibliográficas:}

ARISTÓTELES. Ética a Nicômaco. Tradução de Leonel Vallandro e Gerd Bornheim. São Paulo: Abril S. A. Cultural, 1984.

BÍBLIA. Bíblia de Jerusalém. São Paulo: Paulus, 2002. 
GENTIL, H. S. "Paul Ricœur: A presença do outro". Mente, Cérebro e Filosofia, São Paulo, n. 11, p. 6$15,2008$.

HEGEL, G. W. F. Fenomenologia do espirito. Tradução de Paulo Meneses. Petrópolis: Vozes, 2008.

HÉNAFF, M. Le prix de la vérité: le don, l'argent, la philosophie. Paris: Seuil, 2002.

HOBBES, T. Leviatã ou matéria forma e poder de um estado eclesiástico e civil. Tradução de João Paulo Monteiro e Maria Beatriz Nizza da Silva. São Paulo: Abril Cultural, 1983.

HONNETH, A. Luta por reconbecimento: a gramática moral dos conflitos sociais. Tradução de Luiz Repa. São Paulo: Editora 34, 2003.

HUSSERL, E. Meditações cartesianas: introdução à fenomenologia. Tradução Maria Goreti Lopes e Souza. Porto: RÉS, 1985.

KANT, I. Fundamentação da metafísica dos costumes. Tradução de Paulo Quintela. Lisboa: Edições 70, LDA, 2007.

LÉVINAS, E. Totalidade e infinito. Tradução de José Pinto Ribeiro. Lisboa: Edições 70, 1980.

MAUSS, M. Sociologie et anthopologie. Paris: PUF, 1950.

MOUNIER, E. O Personalismo. Tradução de João Bérnard da Costa. Lisboa: Livraria Morais, 1964.

NIETZSCHE, F. Fragmentos póstumos. Tradução de Germán Meléndez Acuña. Bogotá: Editora Norma, 1997.

RICCEUR, P. "A luta por reconhecimento e a economia do dom”. Tradução de Cláudio Reichert do Nascimento e Noeli Dutra Rossatto. Ethic@, Florianópolis, v. 9, n. 2, p. 357-367, 2010. Disponível em: <https://periodicos.ufsc.br/index.php/ethic/article/view/16772954.2010v9n2p357/18737>. Acesso em: 03 fev. 2015.

- A memória, a história, o esquecimento. Tradução de Alain François. Campinas: Editora da UNICAMP, 2007.

.Du texte à l'action: essais d'herméneutique II. Paris: Seuil, 1986.

.História e Verdade. Tradução de F. A. Ribeiro. Rio de Janeiro: Forense, 1968. 
_; CHANGEUX, J. P. La naturaleza y la norma: lo que nos hace pensar. México: Fondo de Cultura Económica, 2001.

. Na escola da fenomenologia. Tradução de Ephraim Ferreira Alves. Rio de Janeiro: Vozes, 2009. . O si-mesmo como um outro. Tradução de Lucy Moreira Cesar. Campinas: Papirus, 1991.

. Percurso do reconhecimento. Tradução de Nicolás Nyimi Campanário. São Paulo: Loyola, 2006.

Soi-même comme un autre. Paris: Seuil, 1990.

ROSSATTO, N. D. "Viver bem”. Mente, Cérebro e Filosofia, São Paulo, n. 11, p. 26-33, 2008.

SOARES, J. S. Consciência-de-si e reconbecimento na Fenomenologia do espírito e suas implicações na filosofia do direito. 2009. 312 f. Tese (Doutorado em Filosofia)-Universidade Federal do Rio Grande do Sul, Porto Alegre, 2009. Disponível em: <http://www.lume.ufrgs.br/bitstream/handle/10183/16899/000707494.pdf>. Acesso em: 14 jan. 2015. 